\title{
Influence of the number of cycles on shear fatigue strength of resin composite bonded to enamel and dentin using dental adhesives in self-etching mode
}

\author{
Akimasa TSUJIMOTO1,2, Wayne W. BARKMEIER², Robert L. ERICKSON², Toshiki TAKAMIZAWA², Mark A. LATTA ${ }^{2}$ \\ and Masashi MIYAZAKI ${ }^{1}$ \\ ${ }^{1}$ Department of Operative Dentistry, Nihon University School of Dentistry, 1-8-13 Kanda-Surugadai, Chiyoda-ku, Tokyo 101-8310, Japan \\ ${ }^{2}$ Department of General Dentistry, Creighton University School of Dentistry, 2500 California Plaza, Omaha, NE 68178, USA \\ Corresponding author, Akimasa TSUJIMOTO; E-mail: tsujimoto.akimasa@nihon-u.ac.jp
}

\begin{abstract}
The influence of the number of cycles on shear fatigue strength to enamel and dentin using dental adhesives in self-etch mode was investigated. A two-step self-etch adhesive and two universal adhesives were used to bond to enamel and dentin in self-etch mode. Initial shear bond strength and shear fatigue strength to enamel and dentin using the adhesive in self-etch mode were determined. Fatigue testing was used with $20 \mathrm{~Hz}$ frequency and cycling periods of 50,000, 100,000 and 1,000,000 cycles, or until failure occurred. For each of the cycling periods, there was no significant difference in shear fatigue strength across the cycling periods for the individual adhesives. Differences in shear fatigue strength were found between the adhesives within the cycling periods. Regardless of the adhesive used in self-etch mode for bonding to enamel or dentin, shear fatigue strength was not influenced by the number of cycles used for shear fatigue strength testing.
\end{abstract}

Keywords: Shear fatigue strength, Number of cycles, Dental adhesive, Enamel bonding, Dentin bonding

\section{INTRODUCTION}

Numerous laboratory and clinical evaluations of dental adhesives have been conducted since Buonocore ${ }^{1)}$ introduced the concept of phosphoric acid conditioning of enamel in order to bond an acrylic resin to an acidaltered surface. Since that time, there has been rapid advancement of the science in both resin composites ${ }^{2)}$ and dental adhesives ${ }^{3,4)}$.

Early laboratory studies of dental adhesives focused primarily on the determination of shear bond strength of resin composite bonded to phosphoric acid pre-etched enamel ${ }^{5,6}$. Adhesive bonding to dentin remained a challenge for many more years and much controversy has ensued about use of acid pre-treatments on the dentin surface and chemical bonding to enhance the bond ability to the dentin substrate ${ }^{7,8)}$.

Most of the laboratory bond strength evaluations of dental adhesives over the years have been conducted using shear, tensile, or push-out and pull-out methodologies ${ }^{9,10}$. Shear and tensile bond strength tests are typically conducted using a monotonically increasing load where static stress is applied continuously until failure occurs ${ }^{11,12}$. Recently, Kelly et al. ${ }^{13)}$ and Heintze ${ }^{14)}$ questioned whether shear and tensile bond strength tests provide clinically relevant information and have noted a lack of standardization of the tests between research groups. DeHoff et $a l^{9)}$ also argued that traditional bond strength testing results have limited clinical relevance and should not be used to make clinical inferences. However, despite these concerns about static bond strength testing, it remains a popular method for screening the bonding effectiveness of new dental adhesives ${ }^{10)}$.

While shear and tensile bond strength testing provide useful information regarding the ability of dental adhesives to adhesively bond to various substrates, fatigue testing may offer a better alternative to relate bonding effectiveness to the type of repeated sub-critical loading challenges that are encountered in the oral cavity ${ }^{15}$. Cyclic fatigue testing more closely approximates the type of loading stress that may be generated during mastication. Studies have shown that chewing activities in the mouth generally occur in the range of 0.94 to $2.17 \mathrm{~Hz}^{16)}$.

The use of physiologic frequency rates for fatigue strength studies conducted in the laboratory is a challenge because of time requirements. For example, a single specimen run at $2 \mathrm{~Hz}$ for 1,000,000 cycles will take approximately $139 \mathrm{~h}$ to complete the cycling period. Using $5 \mathrm{~Hz}$ the time requirement is about $56 \mathrm{~h}$, the $10 \mathrm{~Hz}$ requirement is about $28 \mathrm{~h}$, and the $20 \mathrm{~Hz}$ requirement is $14 \mathrm{~h}$. Wiskott et al. ${ }^{11)}$ have recommended that fatigue testing should be conducted using 1,000,000 cycles to provide clinical relevance. At lower frequencies (i.e. 1 to $2 \mathrm{~Hz}$ ) and 1,000,000 cycles, the time requirement to conduct a series of tests is very extensive. Thus, there is significant interest in increasing the frequency rate above the physiologic rate and reducing the number of cycles to expedite fatigue testing.

Accelerating fatigue strength testing can involve using higher frequency loading rates and/or reducing the length of the cycling period. Studies conducted on resin composite bonded to enamel and dentin using frequencies of 5,10 and $20 \mathrm{~Hz}$ until failure occurs, or 50,000 cycles are completed, have been reported by Takamizawa et $a l .{ }^{17)}$, and Scheidel et al. ${ }^{18)}$. These studies have shown that there was not a significant difference $(p>0.05)$ in shear fatigue strength among these three frequency rates used for bonding a resin composite to enamel or 
dentin using three adhesives in self-etch mode. However, the question begs -will this hold true if the cycling period is increased to 100,000 or $1,000,000$ cycles?

The purpose of this study was to determine shear fatigue strengths of a resin composite bonded to enamel and dentin using three adhesives in self-etch mode using frequency of $20 \mathrm{~Hz}$ and cycling periods of 50,000, 100,000 and 1,000,000 cycles. The alternative hypothesis posed is that using longer cycling times will significantly lower shear fatigue strength.

\section{MATERIALS AND METHODS}

\section{Study material}

Three dental adhesives were used in this study in selfetch mode and are shown in Table 1. The adhesives used were: a two-step self-etch adhesive 1) OptiBond XTR (OX) [Kerr, Orange, CA, USA], and two universal adhesives 2) Scotchbond Universal (SU) [3M ESPE, St. Paul, MN, USA] and 3) G-Premio Bond (GP) [GC, Tokyo, Japan]. A resin composite, Z100 Restorative (Z100) [3M ESPE], was used for the bonding procedures.

\section{Specimen preparation}

The experimental protocol for using de-identified human molar teeth was reviewed and approved by the Biomedical Institutional Review Board at Creighton University, Omaha, NE, USA (\#760765-1). Sectioned buccal and lingual halves of de-identified extracted human teeth with the apical portion removed were mounted in $25 \mathrm{~mm}$ brass rings with Bosworth Fastray acrylic material (The Harry J. Bosworth, Skokie, IL, USA). Flat enamel and dentin bonding sites were prepared on the mounted buccal and lingual surfaces by wet grinding to 4000 grit using a sequence of silicon carbide papers (Struers, Cleveland, OH, USA) in a grinder-polisher (Ecomet 4, Buehler, Lake Bluff, IL, USA).

Stainless steel metal rings (mold-enclosed method) with an inner diameter of $2.4 \mathrm{~mm}$, an outer diameter of $4.8 \mathrm{~mm}$, and a height of $2.6 \mathrm{~mm}$ were used to bond a resin composite (Z100) to the flat ground enamel and dentin surfaces. The bonding site surfaces (bottom side) of the metal rings were treated with a releasing agent (3\% paraffin in hexane). The flat ground enamel and dentin bonding sites were then treated with the adhesives according to the manufacturers' directions in self-etch mode (Table 2). A custom fixture was used to position and hold the metal rings over the bonding sites, and Z100 resin composite was placed into the rings using a condensing instrument. The resin composite was light polymerized for $40 \mathrm{~s}$ at a standardized distance of $1 \mathrm{~mm}$ using a quartz-tungsten-halogen light curing unit (Spectrum 800 Curing Unit, DENTSPLY Caulk, Milford, DE, USA) set at $600 \mathrm{~mW} / \mathrm{cm}^{2}$, and the bonded specimens were stored in distilled water for $24 \mathrm{~h}$ before testing.

Table 1 Materials, components and study codes

\begin{tabular}{|c|c|c|c|}
\hline $\begin{array}{l}\text { Materials } \\
\text { (Lot. No) }\end{array}$ & $\begin{array}{l}\text { Type of Material } \\
\text { (Code) }\end{array}$ & Main Components & Manufacturer \\
\hline $\begin{array}{l}\text { OptiBond } \\
\text { XTR } \\
\text { (Primer: } \\
\text { 5093728, } \\
\text { Adhesive: } \\
\text { 5093730) }\end{array}$ & $\begin{array}{l}\text { Two-step } \\
\text { self-etch } \\
\text { adhesive (OX) }\end{array}$ & $\begin{array}{l}\text { Primer: GPDM, Phosphate monomer, HEMA, Dimethacrylate } \\
\text { monomers, Acetone, Ethyl alcohol, Water, Initiator } \\
\text { Adhesive: Dimethacrylate monomers, Ethyl alcohol, } \\
\text { Barium aluminoborosilicate glass, Fumed silica, } \\
\text { Sodium hexafluorosilicate, initiator }\end{array}$ & $\begin{array}{l}\text { Kerr, Orange, } \\
\text { CA, USA }\end{array}$ \\
\hline $\begin{array}{l}\text { Scotchbond } \\
\text { Universal } \\
\text { Adhesive } \\
(617265)\end{array}$ & $\begin{array}{l}\text { Single-step } \\
\text { adhesive (SU) }\end{array}$ & $\begin{array}{l}\text { Bis-GMA, HEMA, Decamethylene dimethacrylate, } \\
\text { Ethyl methacryalate, Propenoic acid, Methyl-reaction products } \\
\text { with decanediol and phosphorous oxide, Copolymer of acrylic } \\
\text { and itaconic acid, Dimethylaminobenzoate, Methyl ethyl ketone, } \\
\text { ethanol, water, silane treated silica, initiator }\end{array}$ & $\begin{array}{l}\text { 3M ESPE, } \\
\text { St. Paul, } \\
\text { MN, USA }\end{array}$ \\
\hline $\begin{array}{l}\text { G-Premio } \\
\text { Bond } \\
(1603091)\end{array}$ & $\begin{array}{l}\text { Single-step } \\
\text { adhesive (GP) }\end{array}$ & $\begin{array}{l}\text { MDP, 4-MET, MEPS, Methacrylate monomer, } \\
\text { Acetone, Water, Silica, Initiator }\end{array}$ & $\begin{array}{l}\text { GC, } \\
\text { Tokyo, Japan }\end{array}$ \\
\hline $\begin{array}{l}\text { Z100 } \\
\text { Restorative } \\
\text { (Shade A2, } \\
\text { N725536) }\end{array}$ & $\begin{array}{l}\text { Resin } \\
\text { composite }\end{array}$ & $\begin{array}{l}\text { Bis-GMA, TEGDMA, Silane treated ceramics, } \\
\text { Initiator, Pigments }\end{array}$ & 3M ESPE \\
\hline
\end{tabular}


Table 2 Application protocol for tested adhesives

\begin{tabular}{cl}
\hline Adhesive & \multicolumn{1}{c}{ Adhesive application protocol } \\
\hline OX & $\begin{array}{l}\text { Primer applied to air-dried enamel/dentin surface with rubbing action for } 20 \mathrm{~s} \text {. Medium air } \\
\text { pressure applied to surface for } 5 \mathrm{~s} \text {. Adhesive applied to primed surface with rubbing action } \\
\text { for } 15 \mathrm{~s} \text { and then air thinned for } 5 \mathrm{~s} \text {. Adhesive photo-polymerized for } 10 \mathrm{~s} .\end{array}$ \\
$\mathrm{SU}$ & $\begin{array}{l}\text { Adhesive applied to air-dried enamel/dentin surface with rubbing action for } 20 \mathrm{~s} \text { and then } \\
\text { medium air pressure applied to surface for } 5 \mathrm{~s} \text {. Adhesive photo-polymerized for } 10 \mathrm{~s} .\end{array}$ \\
$\mathrm{GP}$ & $\begin{array}{l}\text { Adhesive applied to air-dried enamel/dentin surface for } 10 \mathrm{~s} \text { and then maximum air } \\
\text { pressure applied to surface for } 5 \mathrm{~s} \text {. Adhesive photo-polymerized for } 10 \mathrm{~s} .\end{array}$ \\
\hline
\end{tabular}

\section{Initial shear bond strength testing}

Initial shear bond strength tests (water storage for $24 \mathrm{~h}$ at $37^{\circ} \mathrm{C}$ ) were first completed with the three adhesives for both enamel and dentin in self-etch mode using the stainless steel ring (mold-enclosed method). A chiselshaped metal rod was used to apply the load on the metal rings immediately adjacent to the flat ground enamel and dentin surfaces. The specimens (15 per group) were loaded to failure using an ElectroPuls E1000 machine (Instron Worldwide Headquarters, Norwood, MA, USA) with a crosshead speed of $1 \mathrm{~mm} / \mathrm{min}$. The initial shear bond strength (MPa) was calculated from the peak load at failure divided by the bonded surface area.

\section{Shear fatigue strength testing}

A staircase method of fatigue testing, previously described by Draughn ${ }^{19)}$, Collins ${ }^{20)}$ and Dewji et al. ${ }^{21)}$, was used to conduct the shear fatigue strength tests with the ElectroPuls E1000 machine. A frequency of 20 $\mathrm{Hz}$ was used with cycling periods of 50,000, 100,000 and $1,000,000$ cycles or until failure occurred. For the shear fatigue strength tests, 20 specimens were prepared for each of the three adhesives being tested on enamel and dentin in self-etch mode. Subsequently, the specimens were stored in distilled water for $24 \mathrm{~h}$ before testing.

The fatigue load was applied using a sine wave for the designated cycling periods used in this study or until failure occurred. The initial peak load for shear fatigue strength testing for each of the adhesives was set at a level approximately one-half of the mean initial shear bond strength determined for each of the three adhesives. The lower load was set near zero $(0.4 \mathrm{~N})$. Subsequent loading was adjusted upward or downward approximately $10 \%$ from the previous load depending on specimen survival or failure. The test specimens were immersed in room temperature water $\left(23 \pm 2^{\circ} \mathrm{C}\right)$ during shear fatigue strength testing. The mean shear fatigue strength (X), and its standard deviation (S), were calculated by the formulae listed below ${ }^{19)}$. Xo is the lowest stress level considered in the analysis, $d$ is the stress increment employed in the sequential tests. The lowest stress level at which a failure occurs is denoted by $i=0$, the next by $i=1$, etc. $n_{i}$ is the number of failures after shear bond fatigue strength tests in at each increment.

$$
\begin{aligned}
& \mathrm{X}=\mathrm{Xo}+\mathrm{d}\left(\frac{\mathrm{A}}{\mathrm{N}}-\frac{1}{2}\right) \\
& \mathrm{S}=1.62 \mathrm{~d}\left(\frac{\mathrm{NB}-\mathrm{A}^{2}}{\mathrm{~N}^{2}}+0.029\right) \\
& \mathrm{N}=\sum n_{i}, \mathrm{~A}=\sum i n_{i}, \mathrm{~B}=\sum i^{2} n_{i}
\end{aligned}
$$

\section{Shear bond strength of surviving specimens shear fatigue} strength testing

Following the completion of the shear fatigue strength testing, the shear bond strengths of the surviving specimens were determined with the ElectroPuls E1000 machine using a crosshead speed of $1.0 \mathrm{~mm} / \mathrm{min}$.

Failure mode of specimens after shear bond strength and shear fatigue strength tests

The bond failure sites after initial shear bond strength and shear fatigue strength tests were assessed using an optical microscope (MZ16, Leica Microsystems, Heerbrugg, Switzerland) at $20 \times$ magnification. The proportion of the resin composite surface with adherent enamel and dentin, and visible residues was classified as 1) adhesive failure at the tooth interface, 2) cohesive failure in resin composite, 3) cohesive failure in enamel or dentin, and 4) mixed failure (partially adhesive and partially cohesive failure).

\section{Statistical analysis}

The initial shear bond strength data for both the enamel and dentin subsets was analyzed using a one-way analysis of variance (ANOVA) followed by Tukey's post hoc test. The survivor specimens were analyzed with a two-way ANOVA [factors of 1) adhesive system and 2) number of cycles] followed by Tukey's post hoc test. The ANOVAs and Tukey's post hoc tests were completed using Systat software (Version 11, Point Richmond, CA, USA). The shear fatigue strength data were analyzed using a modified $t$-test with a Bonferroni correction (custom program). A complex chi-square test was used for the statistical analysis of the failure/ fracture mode for both the enamel and dentin specimens after initial bond strength and shear fatigue strength tests. The chi square analysis was accomplished using an online program (Calculations for the Chi-Square Test, www.quantspy.org/chisq/chisq.htm). 


\section{RESULTS}

\section{Initial shear bond strength}

The results for the initial shear bond strength for the three adhesives to enamel and dentin in self-etch mode are shown in Table 3. The one-way ANOVA test for initial shear bond strength of three adhesives to enamel and dentin found a significant effect for adhesive $(p<0.05)$ and Tukey's post hoc test showed differences among the adhesives. The initial shear bond strength of OX to enamel and dentin was significantly higher $(p<0.05)$ than those of the universal adhesives (SU and GP). The initial shear bond strength of the universal adhesives to enamel was not influenced $(p>0.05)$ by the type of adhesive, but the initial shear bond strength of SU to dentin was higher $(p<0.05)$ than that of GP.

\section{Shear fatigue strength}

The results for the influence of number of cycles on shear fatigue strength of the three adhesives to enamel and dentin in self-etch mode are shown in Table 3. The modified $t$-test with Bonferroni correction for shear fatigue strengths of the three adhesives to enamel did not show any significant differences among the adhesives and number of cycles. The statistical analysis for shear fatigue strength to dentin also did not show any significant difference for each of the individual adhesives across the three cycling periods. However, significant differences in shear fatigue strength to dentin were noted among the adhesives within each of the three cycling periods. Within each of the three cycling periods, the shear fatigue strengths of OX and SU to dentin were significantly higher than that of GP.

Failure mode analysis - Initial shear bond strength and shear fatigue strength tests

The results of the failure mode analysis of de-bonded specimens for initial shear bond strength and shear fatigue strength tests to enamel and dentin in self-etch mode are shown in Table 4. For the failure mode analysis of de-bonded specimens from initial shear bond strength tests to enamel, adhesive failure was the predominant mode of failure regardless of the type of adhesive. The failure mode analysis of de-bonded specimens from shear fatigue strength tests to enamel also showed primarily adhesive failures and no significant differences $(p>0.05)$

Table 3 Initial shear bond strength $(\mathrm{MPa})$ and shear fatigue strength $(\mathrm{MPa})$ of adhesives systems

\begin{tabular}{|c|c|c|c|c|c|}
\hline \multirow{2}{*}{ Substrate } & \multirow{2}{*}{ Adhesive } & \multirow{2}{*}{$\begin{array}{l}\text { Initial shear } \\
\text { bond strength }\end{array}$} & \multicolumn{3}{|c|}{ Shear fatigue strength } \\
\hline & & & 50,000 cycles & 100,000 cycles & $1,000,000$ cycles \\
\hline \multirow{3}{*}{ Enamel } & OX & $34.3(4.0)^{\mathrm{a}}$ & $15.7(2.6)^{\mathrm{a}, \mathrm{A}}$ & $17.0(3.0)^{\mathrm{a}, \mathrm{A}}$ & $17.1(3.0)^{\mathrm{a}, \mathrm{A}}$ \\
\hline & SU & $27.2(2.3)^{\mathrm{b}}$ & $13.9(3.5)^{\mathrm{a}, \mathrm{A}}$ & $13.8(2.7)^{\mathrm{a}, \mathrm{A}}$ & $12.7(3.9)^{\mathrm{a}, \mathrm{A}}$ \\
\hline & GP & $26.1(2.4)^{\mathrm{b}}$ & $13.8(2.4)^{\mathrm{a}, \mathrm{A}}$ & $13.0(2.0)^{\mathrm{a}, \mathrm{A}}$ & $13.1(1.2)^{\mathrm{a}, \mathrm{A}}$ \\
\hline \multirow{3}{*}{ Dentin } & OX & $51.0(5.0)^{\mathrm{a}}$ & $23.5(3.2)^{\mathrm{a}, \mathrm{A}}$ & $22.7(2.3)^{\mathrm{a}, \mathrm{A}}$ & $21.4(1.3)^{\mathrm{a}, \mathrm{A}}$ \\
\hline & SU & $41.7(4.9)^{\mathrm{b}}$ & $20.4(2.9)^{\mathrm{a}, \mathrm{A}}$ & $18.8(1.5)^{\mathrm{a}, \mathrm{b}, \mathrm{A}}$ & $18.3(5.5)^{\mathrm{a}, \mathrm{b}, \mathrm{A}}$ \\
\hline & GP & $27.7(3.9)^{\mathrm{c}}$ & $14.6(2.5)^{\mathrm{b}, \mathrm{A}}$ & $16.9(1.7)^{\mathrm{b}, \mathrm{A}}$ & $14.9(2.4)^{\mathrm{b}, \mathrm{A}}$ \\
\hline
\end{tabular}

Values in parenthesis are standard deviation. Same small letter in same column indicates of each substrate no significant difference $(p>0.05)$. Same capital letter within individual rows of each substrate indicates no significant difference $(p>0.05)$.

Table 4 Failure mode analysis of de-bonded specimens after initial shear bond strength and shear fatigue strength tests

\begin{tabular}{|c|c|c|c|c|c|}
\hline \multirow{2}{*}{ Substrate } & \multirow{2}{*}{ Adhesive } & \multirow{2}{*}{$\begin{array}{l}\text { Initial shear bond } \\
\text { strength }\end{array}$} & \multicolumn{3}{|c|}{ Shear fatigue strength } \\
\hline & & & 50,000 cycles & 100,000 cycles & $1,000,000$ cycles \\
\hline \multirow{3}{*}{ Enamel } & OX & {$[100 / 0 / 0 / 0]^{\mathrm{a}}$} & {$[100 / 0 / 0 / 0]^{\mathrm{a}, \mathrm{A}}$} & {$[85 / 0 / 10 / 5]^{\mathrm{a}, \mathrm{A}}$} & {$[95 / 0 / 5 / 0]^{\mathrm{a}, \mathrm{A}}$} \\
\hline & SU & {$[100 / 0 / 0 / 0]^{\mathrm{b}}$} & {$[100 / 0 / 0 / 0]^{\mathrm{a}, \mathrm{A}}$} & {$[100 / 0 / 0 / 0]^{\mathrm{a}, \mathrm{A}}$} & {$[95 / 0 / 0 / 5]^{\mathrm{a}, \mathrm{A}}$} \\
\hline & GP & {$[100 / 0 / 0 / 0]^{\mathrm{b}}$} & {$[90 / 0 / 10 / 0]^{\mathrm{a}, \mathrm{A}}$} & {$[75 / 0 / 25 / 0]^{\mathrm{a}, \mathrm{A}}$} & {$[95 / 0 / 0 / 5]^{\mathrm{a}, \mathrm{A}}$} \\
\hline \multirow{3}{*}{ Dentin } & OX & {$[68 / 19 / 13 / 0]^{\mathrm{a}}$} & {$[60 / 20 / 10 / 10]^{\mathrm{a}, \mathrm{A}}$} & {$[65 / 20 / 15 / 0]^{\mathrm{a}, \mathrm{A}}$} & {$[65 / 20 / 15 / 0]^{\mathrm{a}, \mathrm{A}}$} \\
\hline & SU & {$[74 / 19 / 7 / 0]^{\mathrm{b}}$} & {$[60 / 30 / 5 / 5]^{\mathrm{a}, \mathrm{A}}$} & {$[55 / 30 / 10 / 5]^{\mathrm{a}, \mathrm{A}}$} & {$[50 / 20 / 25 / 5]^{\mathrm{a}, \mathrm{A}}$} \\
\hline & GP & {$[100 / 0 / 0 / 0]^{\mathrm{c}}$} & {$[100 / 0 / 0 / 0]^{\mathrm{b}, \mathrm{A}}$} & {$[95 / 0 / 5 / 0]^{\mathrm{a}, \mathrm{A}}$} & {$[90 / 10 / 0 / 0]^{\mathrm{a}, \mathrm{A}}$} \\
\hline
\end{tabular}

Percentage of failure mode [adhesive failure/ cohesive failure in resin composite/ cohesive failure in dentin/ mixed failure]. Same small letter in same column indicates no significant difference $(p>0.05)$. Same capital letter within individual rows indicates no significant difference $(p>0.05)$. 
were found between the adhesives and number of cycles.

The failure mode of de-bonded specimens from initial shear bond strength and shear fatigue strength tests to dentin showed more cohesive and mix failures for both OX and SU, but not for GP. There was no significant difference $(p>0.05)$ in the type of failure mode for initial shear bond strength and shear fatigue strength tests to dentin among the adhesives and number of cycles.

Shear bond strength of survivors after shear fatigue strength test

The results for the shear bond strength of survivors after shear fatigue strength tests to enamel and dentin in self-etch mode are shown in Table 5. The two-way ANOVA for the shear bond strength of survivors after shear fatigue strength tests to enamel and dentin showed a significant influence $(p<0.001)$ for the factors of adhesive, but no significant difference for the number of cycles and interaction of adhesive or number of cycles $(p>0.05)$. The shear bond strengths of survivors after shear fatigue strength tests to enamel were similar $(p>0.05)$ to the initial shear bond strength for OX and significantly higher $(p<0.05)$ than the initial shear bond strengths for SU and GP. The shear bond strengths of survivors after shear fatigue strength tests to enamel was not influenced $(p>0.05)$ by the number of cycles, and the shear bond strengths of survivors after shear fatigue strength tests of OX to enamel were significantly higher $(p<0.05)$ than those of universal adhesives, as for the initial shear bond strength.

The shear bond strengths to dentin of survivors after shear fatigue strength tests were similar $(p>0.05)$ to the initial shear bond strengths for OX or GP and significantly higher $(p<0.05)$ than the initial shear bond strength for SU. The shear bond strengths of survivors

Table 5 Comparison of initial shear bond strength $(\mathrm{MPa})$ and shear bond strength of survivors (MPa) after shear fatigue strength tests

\begin{tabular}{|c|c|c|c|c|c|c|c|c|}
\hline \multirow{3}{*}{ Substrate } & \multirow{3}{*}{ Adhesive } & \multirow{3}{*}{$\begin{array}{l}\text { Initial } \\
\text { shear } \\
\text { bond } \\
\text { strength }\end{array}$} & \multicolumn{6}{|c|}{ Shear fatigue strength } \\
\hline & & & \multicolumn{2}{|c|}{50,000 cycles } & \multicolumn{2}{|c|}{100,000 cycles } & \multicolumn{2}{|c|}{$1,000,000$ cycles } \\
\hline & & & $\begin{array}{l}\text { Shear bond } \\
\text { strength of } \\
\text { survivors }\end{array}$ & $\begin{array}{c}\text { Percent of } \\
\text { specimens } \\
\text { survived (\%) }\end{array}$ & $\begin{array}{l}\text { Shear bond } \\
\text { strength of } \\
\text { survivors }\end{array}$ & $\begin{array}{c}\text { Percent of } \\
\text { specimens } \\
\text { survived (\%) }\end{array}$ & $\begin{array}{l}\text { Shear bond } \\
\text { strength of } \\
\text { survivors }\end{array}$ & $\begin{array}{c}\text { Percent of } \\
\text { specimens } \\
\text { survived (\%) }\end{array}$ \\
\hline \multirow{3}{*}{ Enamel } & OX & $34.3(4.0)^{\mathrm{a}}$ & $37.8(5.8)^{\mathrm{a}, \mathrm{A}}$ & 50 & $38.7(6.5)^{\mathrm{a}, \mathrm{A}}$ & 45 & $38.5(5.2)^{\mathrm{a}, \mathrm{A}}$ & 45 \\
\hline & SU & $27.2(2.3)^{\mathrm{b}}$ & $31.0(3.1)^{\mathrm{b}, \mathrm{B}}$ & 30 & $31.4(4.4)^{\mathrm{b}, \mathrm{B}}$ & 30 & $32.9(4.1)^{\mathrm{b}, \mathrm{B}}$ & 40 \\
\hline & GP & $26.1(2.4)^{\mathrm{b}}$ & $32.2(5.2)^{\mathrm{b}, \mathrm{B}}$ & 70 & $31.4(5.6)^{\mathrm{b}, \mathrm{B}}$ & 55 & $32.0(5.0)^{\mathrm{b}, \mathrm{B}}$ & 50 \\
\hline \multirow{3}{*}{ Dentin } & OX & $51.0(5.0)^{\mathrm{a}}$ & $53.6(7.2)^{\mathrm{a}, \mathrm{A}}$ & 60 & $53.3(6.1)^{\mathrm{a}, \mathrm{A}}$ & 55 & $52.5(9.3)^{\mathrm{a}, \mathrm{A}}$ & 45 \\
\hline & SU & $41.7(4.9)^{\mathrm{b}}$ & $51.2(5.5)^{\mathrm{a}, \mathrm{B}}$ & 65 & $49.7(7.6)^{\mathrm{a}, \mathrm{B}}$ & 45 & $52.7(6.2)^{\mathrm{a}, \mathrm{B}}$ & 50 \\
\hline & GP & $27.7(3.9)^{\mathrm{c}}$ & $29.2(5.3)^{\mathrm{b}, \mathrm{A}}$ & 50 & $30.7(6.0)^{\mathrm{b}, \mathrm{A}}$ & 60 & $31.5(6.6)^{\mathrm{b}, \mathrm{A}}$ & 55 \\
\hline
\end{tabular}

Values in parenthesis are standard deviation. Same small letter in same column indicates no significant difference $(p>0.05)$. Same capital letter within individual rows indicates no significant difference $(p>0.05)$.

Table 6 Failure mode analysis of de-bonded specimens for initial shear bond strength and survivors after shear fatigue strength tests

\begin{tabular}{|c|c|c|c|c|c|}
\hline \multirow{2}{*}{ Substrate } & \multirow{2}{*}{ Adhesive } & \multirow{2}{*}{$\begin{array}{l}\text { Initial shear bond } \\
\text { strength }\end{array}$} & \multicolumn{3}{|c|}{ Shear fatigue strength } \\
\hline & & & 50,000 cycles & 100,000 cycles & $1,000,000$ cycles \\
\hline \multirow{3}{*}{ Enamel } & OX & {$[100 / 0 / 0 / 0]^{\mathrm{a}, \mathrm{A}}$} & {$[100 / 0 / 0 / 0]^{a, A}$} & {$[89 / 0 / 11 / 0]^{\mathrm{a}, \mathrm{A}}$} & {$[89 / 0 / 11 / 0]^{\mathrm{a}, \mathrm{A}}$} \\
\hline & SU & {$[100 / 0 / 0 / 0]^{\mathrm{a}, \mathrm{A}}$} & {$[100 / 0 / 0 / 0]^{\mathrm{a}, \mathrm{A}}$} & {$[100 / 0 / 0 / 0]^{\mathrm{a}, \mathrm{A}}$} & {$[87 / 0 / 0 / 13]^{\mathrm{a}, \mathrm{A}}$} \\
\hline & GP & {$[100 / 0 / 0 / 0]^{\mathrm{a}, \mathrm{A}}$} & {$[93 / 0 / 7 / 0]^{\mathrm{a}, \mathrm{A}}$} & {$[100 / 0 / 0 / 0]^{\mathrm{a}, \mathrm{A}}$} & {$[100 / 0 / 0 / 0]^{\mathrm{a}, \mathrm{A}}$} \\
\hline \multirow{3}{*}{ Dentin } & OX & {$[68 / 19 / 13 / 0]^{\mathrm{a}, \mathrm{A}}$} & {$[42 / 33 / 17 / 8]^{\mathrm{a}, \mathrm{B}}$} & {$[28 / 36 / 36 / 0]^{\mathrm{a}, \mathrm{B}}$} & {$[22 / 56 / 0 / 22]^{\mathrm{a}, \mathrm{b}, \mathrm{B}}$} \\
\hline & SU & {$[74 / 19 / 7 / 0]^{a, A}$} & {$[46 / 46 / 8 / 0]^{a, b, B}$} & {$[0 / 67 / 22 / 11]^{a, \mathrm{~B}}$} & {$[20 / 50 / 20 / 10]^{\mathrm{a}, \mathrm{B}}$} \\
\hline & GP & {$[100 / 0 / 0 / 0]^{\mathrm{a}, \mathrm{A}}$} & {$[100 / 0 / 0 / 0]^{\mathrm{b}, \mathrm{A}}$} & {$[95 / 0 / 5 / 0]^{\mathrm{b}, \mathrm{A}}$} & {$[82 / 18 / 0 / 0]^{\mathrm{b}, \mathrm{A}}$} \\
\hline
\end{tabular}

Percentage of failure mode [adhesive failure/cohesive failure in resin composite/cohesive failure in dentin/mixed failure]. Same small letter in same column indicates no significant difference $(p>0.05)$. Same capital letter within individual rows indicates no significant difference $(p>0.05)$. 
after shear fatigue strength tests of OX and SU were significantly higher $(p<0.05)$ than those of GP, as for the initial shear bond strength. The shear bond strengths of survivors after shear fatigue strength tests to dentin were not influenced $(p>0.05)$ by the number of cycles, and the shear bond strengths of survivors of OX and SU after shear fatigue strength tests to dentin were significantly higher $(p<0.05)$ than those of GP.

\section{Failure mode analysis of survivors after shear fatigue strength tests}

The results of failure mode analysis of de-bonded specimens for the survivors after shear fatigue strength tests to enamel and dentin in self-etch mode are shown in Table 6. For the failure mode of de-bonded specimens from the survivors after shear fatigue strength tests to enamel, adhesive failure was the predominant mode of failure regardless of the type of adhesive and number of cycles and no significant differences $(p>0.05)$ were found between the adhesives and number of cycles.

The failure mode of de-bonded specimens of $\mathrm{OX}$ and SU from the survivors after shear fatigue strength tests to dentin showed fewer adhesive failures and more cohesive and mixed failures, while the failure mode of GP was primarily adhesive failures. However, the failure mode of de-bonded specimens from the survivors after shear fatigue strength tests to dentin was not influenced $(p>0.05)$ by the number of cycles.

\section{DISCUSSION}

Evaluation of the bonding characteristics of dental adhesives has been of significant interest to the profession over the last several decades. Both researchers and clinicians are concerned about the long term endurance of dental materials bonded to mineralized tooth structures. In the past, bonding to the enamel substrate was achieved primarily via phosphoric acid etching of the surface, followed by an adhesive to create a micromechanical bond to the altered surface ${ }^{1)}$. Bonding to dentin has been much more challenging because of the nature of the substrate. The evolution of adhesives designed to enhance bonding to both enamel and dentin has ushered in an era of materials designed to self-etch both substrates and bond through both micromechanical and chemical adhesion ${ }^{4}$. Manufacturers are now aggressively promoting self-etch adhesives for bonding to enamel and dentin without phosphoric acid preetching of enamel. Most manufacturers currently do not even include a phosphoric acid etchant in their kit packages.

Fatigue testing in the laboratory has been used to help predict the clinical endurance of adhesive bonds. The cyclic stresses used in fatigue testing are more closely associated with physiologic clinical challenges than the continuous loading to failure stress applied in shear bond strength testing. De Munck et al. ${ }^{22)}$ have related that fatigue testing of tooth-biomaterials interfaces theoretically should predict better the in vivo performance of adhesives, when compared to static bond strength tests, and be more clinically relevant.

Various terms have been used to define the endurance value generated in the staircase method of fatigue testing. Collins ${ }^{20)}$ related that staircase testing was a valid method for determining the fatigue limit, which is the fatigue strength at infinite life. Wiskott et $a l .{ }^{11)}$ defined the endurance limit as the stress level at which $50 \%$ of the specimens will survive a predetermined number of cycles. Erickson et al. ${ }^{12)}$ related that the fatigue limit was the stress value that is likely to produce $50 \%$ failures and Takamizawa et al. ${ }^{23)}$ later described this same value as fatigue strength. So, while the definition of the resultant stress value in the staircase test method has been identified somewhat differently over the years, the agreed upon parameter for the endurance stress level or fatigue strength has been consistently identified as the stress at which $50 \%$ of the specimens will fail or survive. The calculations for fatigue strength developed by Draughn ${ }^{19)}$ will accommodate using either failures or survivors.

With the significant interest in fatigue testing for evaluation of the newer generation self-etch adhesives, Erickson et al. ${ }^{24)}$ examined shear fatigue strength to enamel using four self-etch adhesives in self-etch mode and compared these results to a conventional etchand-rinse adhesives. These authors concluded that this laboratory study clearly showed that the self-etch adhesives, when used as recommended, resulted in lower fatigue strengths of a resin composite bonded to enamel than an etch-and-rinse system. A subsequent study by Erickson et al. ${ }^{25)}$ found that phosphoric acid pre-etching of enamel with self-etch adhesives enhanced shear bond strength to levels similar to an etch-andrinse adhesive. More recently, Suzuki et al. ${ }^{26)}$ examined the fatigue strength using $10 \mathrm{~Hz}$ frequency and 50,000 cycles for testing of resin composite bonds to enamel with and without phosphoric acid pre-etching using four universal adhesives. The results of that study also clearly showed significantly greater shear fatigue strength with all four adhesives when used with phosphoric acid pre-etching, when compared to the selfetch mode. For all four universal adhesives the shear fatigue strength was nearly double for the pre-etching mode compared to the self-etch mode. The present study also showed that adhesives used in self-etch mode did not bond to enamel as well as dentin. Evidence is clearly available in the literature to support using phosphoric acid pre-etching of enamel as part of a routine bonding regimen.

While fatigue strength studies on adhesives yield valuable information, they are very time consuming. Previous evidence shows that increasing the frequency rate beyond the physiologic level of 1 to $2 \mathrm{~Hz}$ does not adversely affect the fatigue strength testing for resin composite bonded to enamel or dentin using a stainless steel ring to encase the bonded resin composite ${ }^{17,18)}$. In these studies frequencies of 5,10 and $20 \mathrm{~Hz}$ were used for shear fatigue strength testing of mold-enclosed resin composite bonded to enamel and dentin surfaces using three self-etch adhesives. No significant differences 
were found in shear fatigue strength among the three individual adhesives at 5, 10 or $20 \mathrm{~Hz}$ frequencies. Joshi et al. ${ }^{27)}$ also conducted cyclic fatigue testing on a fluorapatite glass-ceramic at 2 and $10 \mathrm{~Hz}$ frequencies and recorded the number of cycles to failure. These investigators found that there was no difference in the characteristic lifetime between the specimens tested at 2 and $10 \mathrm{~Hz}$ and concluded that sub-critical crack growth of the glass-ceramic was not affected by the testing frequency. They also cautioned that clinicians and researchers should not disregard studies that use higher than physiologic frequencies for evaluations of glass-ceramic materials.

The results of the present study show that there is not a significant difference in the shear fatigue strengths to either enamel or dentin for the three individual adhesives tested across the cycling periods of 50,000 , 100,000 and 1,000,000 cycles. The shear fatigue strengths to enamel also were not statistically different among the three adhesives within each of the three cycling periods. However, significant difference were found among the three adhesives within each of the cycling periods for dentin. For the enamel substrate, the shear fatigue strengths of OX and SU were not statistically different in all three cycling periods, but were greater than GP. With these results, the alternative hypothesis, that longer cycling periods would result in decreased shear fatigue strength, is rejected. The above results suggest that longer cycling periods may not be necessary for establishing the shear fatigue strength, under the methods used in this study. These findings, while counter intuitive, provide evidence that shear fatigue strength testing in an accelerated model (e.g. $20 \mathrm{~Hz}$ frequency and 50,000 cycles) may be as effective as testing at 1,000,000 cycles. From a clinical perspective shear fatigue strength information can be useful for practitioners when selecting materials for their practice. The accelerated model allows information from researchers to be transferred to practitioners in an efficient time frame, while still being relevant for clinicians.

While the main objective of this study was to examine the effect that lengthening the cycling time has on shear fatigue strength was accomplished, as discussed above, there are other factors that need to be examined regarding shear fatigue strength testing. One of the concerns in the shear fatigue strength testing with higher frequencies is the potential for heat generation. In the present study a water reservoir was used to surround the bonded assembly during testing with $20 \mathrm{~Hz}$ frequency. The water heat sink should attenuate any heat generation during testing. Another concern in the shear fatigue strength testing is the chisel-shaped instrument blade used for the load applications directly contacting the bonded material and producing localized stresses. Finite element stress analyses have shown that force applications with a chisel-shaped blade directly on a bonded material contributes to localized stresses ${ }^{28}$. The use of a moldenclosed bonded assembly reduces the potential issues related to localization of stresses when shearing devices directly contact the resin composite during shear bond strength and shear fatigue strength testing. Erickson et al. ${ }^{24,25)}$ introduced a mold-enclosed system (non-deforming metal under loads applied for shear bond strength and shear fatigue strength testing) for determining initial shear bond strength and shear fatigue strength. Stainless steel metal rings were used to encase a resin composite material for bonding to enamel using dental adhesives. Van Meerbeek et al. ${ }^{10)}$ also noted that the SDI jig (metal mold-enclosure) might be considered in approaches for standardization of bond strength testing protocols. Cheetham et al. ${ }^{29)}$ investigated the effect of using a metal mold-enclosed method for determination of micro-shear bond strengths of resin cements bonded to metal. The aim of that study was to distribute the concentrated loading force across the adhesive interface. In theory, the mold-enclosed bonding assembly reduced the effects of the bending moment and potential damage to the cement at the contact area of the blunt-edge knife blade. The point load was distributed around the metal mold reducing the concentration of shear stresses. This resulted in significantly higher bond strengths of resin cements to metal than control specimens without the mold enclosure. Barkmeier et al. ${ }^{30}$ reported similar shear bond strength findings when using a stainless steel metal mold enclosure for bonding resin composite to moist enamel with two etch-and-rinse systems and presented comparative results with specimens bonded with the Ultradent assembly (non-enclosed). The bonded resin composite surface contact areas were approximately the same surface area with both methods. The mold-enclosed shear bond strengths were significantly higher than the non-enclosed specimens and ranged approximately $20 \%$ greater. The study cited above for the resin cement ${ }^{27)}$ and the results of the metal mold-enclosure study for bonding resin composite ${ }^{30}$ ) clearly demonstrate the advantages of using a metal mold-enclosure for shear bond strength and shear fatigue strength studies. Jin et al. ${ }^{31)}$ recently confirmed using finite-element analysis that the mold-enclosed method for shear bond strength testing produces a more uniform stress to the adhesive interface than the nonenclosed method for shear bond strength testing.

Failure mode analysis in the present study also revealed some interesting trends. The failure mode of enamel specimens after shear fatigue strength tests was primarily adhesive in nature and no significant differences were found among the individual adhesive within the three cycling periods or across the cycling periods. This is probably related to the low bond strengths developed to enamel because the adhesives were used in the self-etch mode. These data clearly show poor adhesion to enamel, when phosphoric acid pre-etching is not used. The failure mode of the dentin specimens after shear fatigue tests was clearly different than the enamel results. GP exhibited primary adhesive failures, while the failure pattern of OX and SU revealed more cohesive and mixed failures indicating better adhesion to the substrate. The shear fatigue strengths 
of the OX and SU to dentin were significantly greater than GP in the 50,000 100,000 and 1,000,000 cycles. The higher shear fatigue strength of OX and SU is most likely related to producing more cohesive failures and mixed failure than observed with GP.

Erickson et al. ${ }^{12)}$ reported data from a study examining the shear fatigue strength $(2 \mathrm{~Hz}$ and $1,000,000$ cycles) of resin composite bonded to enamel using an etch-and-rinse adhesive and an early generation self-etch adhesive. They also reported the relationship of initial shear bond strength and the shear bond strength of the surviving specimens after shear fatigue strength testing. The shear bond strength of the surviving specimens was $7.1 \%$ higher than the initial shear bond strength for the etch-and-rinse adhesive and $7.3 \%$ higher for the self-etch adhesive. In the present study the shear bond strength of the surviving specimens after the shear fatigue strength testing was also higher for both enamel and dentin than the initial shear bond strength. The percentage increases of shear bond strength for enamel were $11.7 \%$ for OX, $16.8 \%$ for SU and $22.1 \%$ for GP; percentage increases for dentin were $4.2 \%$ for OX, $22.8 \%$ for SU and $16.7 \%$ for GP. While the percentage increases of shear bond strength were generally higher than reported by Erickson et al. ${ }^{12)}$, it was expected that the shear bond strength of the surviving specimens after fatigue testing would be greater than the initial shear bond strength because these specimens survived the challenges of cyclic loading. However, only SU demonstrated a significant difference in the shear bond strength to dentin of the surviving specimens after the shear fatigue strength testing for each cycling period were compared with the initial shear bond strength. When the failure modes were examined, it was apparent that the specimens for initial shear bond strengths testing demonstrated a predominance of adhesive failures, while the survivors, having a higher shear bond strength, showed a shift toward more cohesive and mixed failures. This suggests that an adhesive mode of failure is more strongly correlated with earlier bond failure during cycling while the survivors are less prone to adhesive failure. This shows up in the failure mode of the specimens for shear fatigue testing as well, where the failure modes are $50-60 \%$ adhesive. Under a cyclic loading regimen, specimens more prone to adhesive failure of the bond are those that are less likely to survive to the maximum number of cycles.

Increasing the number of cycles in shear fatigue strength testing substantially generates more loading moments for the test specimens, but the concern is that, while the use of higher frequencies expedites shear fatigue strength testing, increasing the frequency rates reduces the actual higher loading (85\% of maximum load) contact time during individual cycles. At $20 \mathrm{~Hz}$, the applied load is above $85 \%$ of maximum load for $12,500 \mathrm{~s}$ using $1,000,000$ cycles, $1,250 \mathrm{~s}$ using 100,000 cycles, and 625 seconds using 50,000 cycles. At 50,000 cycles using a frequency of $5 \mathrm{~Hz}$, the load is above $85 \%$ of maximum for $2,500 \mathrm{~s}$ compared to $1,250 \mathrm{~s}$ for $10 \mathrm{~Hz}$ and $625 \mathrm{~s}$ for
$20 \mathrm{~Hz}$. In previous studies of the same materials using 50,000 fatigue cycles, with frequencies of 5, 10 and 20 $\mathrm{Hz}^{17,18)}$, there were no significant differences in shear fatigue strength for each adhesive between the three frequencies. In the present study using 1,000,000 cycles at $20 \mathrm{~Hz}$ provided both more loading moments and longer loading time. This supports the idea that fatigue testing for 50,000 cycles at $20 \mathrm{~Hz}$ may be sufficient under the conditions used in this study. Wiskott et al. ${ }^{11)}$ related that while accelerated shear fatigue strength testing has obvious shortcomings, this type of testing is a necessary component of fatigue testing since time constraints can be alleviated.

The overall results of this study combined with the previously published data ${ }^{17,18)}$ showing that higher frequency testing $(20 \mathrm{~Hz})$ can be used with this moldenclosed testing model for determining shear fatigue strength of a resin composite adhesively bonded to enamel and dentin are important for the design of future shear fatigue strength testing studies. The use of 50,000 cycling versus $1,000,000$ cycles with a $20 \mathrm{~Hz}$ frequency is an efficient time-saving approach for future shear fatigue strength studies using this testing model.

\section{CONCLUSIONS}

Fatigue testing of a resin composite bonded to either enamel or dentin using three adhesives in the self-etch mode with $20 \mathrm{~Hz}$ frequency and cycling periods of 50,000, 100,000 or $1,000,000$ cycles did not show any significant difference in shear fatigue strengths for the individual adhesives across the three cycling periods. The results of this study indicate that under the methodology described the cycling period for shear fatigue strength testing of dental adhesives to enamel and dentin may be reduced from 1,000,000 cycles that is commonly suggested as being clinically relevant, to 50,000 cycles to more efficiently assess the bond fatigue endurance of dental adhesives.

\section{ACKNOWLEDGMENTS}

The authors thank Mr. Jason M. Moody for technical contributions.

\section{REFERENCES}

1) Buonocore MG. A simple method of increasing the adhesion of acrylic filling materials to hard enamel surfaces. J Dent Res 1955; 34: 849-853.

2) Ferracane JL. Resin composite — state of the art. Dent Mater 2011; 27: 29-38.

3) Pashley DH, Tay FR, Breschi L, Tjäderhane L, Carvalho RM, Carrilho M, Tezvergil-Mutluay A. State of the art etch-andrinse adhesives. Dent Mater 2011; 27: 1-16.

4) Van Meerbeek B, Yoshihara K, Yoshida Y, Mine A, De Munck J, Van Landuyt KL. State of the art of self-etch adhesives. Dent Mater 2011; 27: 17-28.

5) Barkmeier WW, Gwinnett AJ, Shaffer SE. Effects of enamel etching time on bond strength and morphology. J Clin Orthod 1985; 19: 36-38.

6) Shaffer SE, Barkmeier WW, Kelsey WP 3rd. Effect of reduced 
acid concentration and etching time on enamel bond strength and morphology. Gen Dent 1987; 35: 278-280.

7) Wei SHY, Barkmeier WW. Conference report: International symposium on adhesives in dentistry. J Dent Res 1992; 71: 75-77.

8) Barkmeier WW, Cooley RL. Laboratory evaluation of adhesive systems. Oper Dent 1992; Suppl 5: 50-61.

9) DeHoff PH, Anusavice KJ, Wang Z. Three-dimensional finite element analysis of the shear bond test. Dent Mater 1985; 11: 126-131.

10) Van Meerbeek B, Peumans M, Poitevin A, Mine A, Van Ende A, Neves A, De Munck J. Relationship between bond-strength tests and clinical outcomes. Dent Mater 2010; 26: e100-e121.

11) Wiskott HW, Nicholls JI, Belser UC. Fatigue resistance of soldered joints: A methodological study. Dent Mater 1994; 10: 215-220.

12) Erickson RL, De Gee AJ, Feilzer AJ. Fatigue testing of enamel bonds with self-etch and total-etch adhesive systems. Dent Mater 2006; 22: 981-987.

13) Kelly JR, Benetti P, Rungruanganunt P, Bona AD. The slippery slope - Critical perspectives on in vitro research methodologies. Dent Mater 2012; 28: 41-51.

14) Heintze SD. Clinical relevance of tests on bond strength, microleakage and marginal adaption. Dent Mater 2013; 29: 59-84.

15) Erickson RL, De Gee AJ, Feilzer AJ. Effect of pre-etching enamel on fatigue of self-etch adhesive bonds. Dent Mater 2008; 24: 117-123.

16) Po JM, Kieser JA, Gallo LM, Tésenyi AJ, Herbison P, Farella $\mathrm{M}$. Time-frequency analysis of chewing activity in the natural environment. J Dent Res 2011; 90: 1206-1210.

17) Takamizawa T, Scheidel DD, Barkmeier WW, Erickson RL, Tsujimoto A, Latta MA, Miyazaki M. Influence of frequency on shear fatigue strength of resin composite to enamel bonds using self-etch adhesives. J Mech Behav Biomed Mater 2016; 62: 291-298.

18) Scheidel DD, Takamizawa T, Barkmeier WW, Erickson RL, Tsujimoto A, Miyazaki M. Effect of frequency on fatigue strength of dentin bonds. J Oral Sci 2016; 58: 539-546.

19) Draughn RA. Compressive fatigue limits of composite restorative materials. J Dent Res 1979; 58: 1093-1096.

20) Collins JA. Failure of materials in mechanical design, 2ed. Chapter 19, Fatigue testing procedures and statistical interpretation of data: 10.7 Staircase or up-and-down method. John Wiley \& sons 1993. p. 383-390.

21) Dewji HR, Drummond JL, Fadavi S, Punwani I. Bond strength of Bis-GMA and glass ionomer pit and fissure sealants using cyclic fatigue. Eur J Oral Sci 1009; 106: 594-599.

22) De Munck J, Braem M, Wevers M, Yoshida Y, Inoue S, Suzuki K. Lambrechts P, Van Meerbeek B. Micro-rotary fatigue of tooth-biomaterials interfaces. Biomaterials 2005; 26: 11451153.

23) Takamizawa T, Barkmeier WW, Tsujimoto A, Scheidel DD, Watanabe H, Erickson RL, Latta MA, Miyazaki M. Influence of water storage on fatigue strength of self-etch adhesives. J Dent 2015; 43: 1416-1427.

24) Erickson RL, Barkmeier WW, Kimmes NS. Fatigue of enamel bonds with self-etch adhesives. Dent Mater 2009; 25: 716720

25) Erickson RL, Barkmeier WW, Latta MA. The role of etching in bonding to enamel: a comparison of self-etching and etchand-rinse adhesive systems. Dent Mater 2009; 25: 11591167.

26) Suzuki T, Takamizawa T, Barkmeier WW, Tsujimoto A, Endo $\mathrm{H}$, Erickson RL, Latta, MA, Miyazaki M. Influence of etching mode on enamel bond durability of universal adhesive systems. Oper Dent 2016; 41: 520-530.

27) Joshi GV, Duan Y, Della Bona A, Hill TJ, St. John K, Griggs JA. Contributions of stress corrosion and cyclic fatigue to subcritical crack growth in a dental glass-ceramic. Dent Mater 2014; 30: 884-890.

28) Placido E, Meira JBC, Lima RG, Muench A, de Souza RM, Ballester RY. Shear versus micro-shear bond strength test: a finite element stress analysis. Dent Mater 2007; 23: 10861092.

29) Cheetham JJ, Palamara, JES, Tyas MJ, Burrow MF. A comparison of the shear bond strength and failure mode to metals of unsupported and supported luting cement specimens. J Adhes Dent 2014; 16: 251-260.

30) Barkmeier WW, Erickson RL, Latta MA. Fatigue limits of enamel bonds with moist and dry techniques. Dent Mater 2009; 26: 1527-1531.

31) Jin XN, Homaei E, Matinlinna JP, Tsoi JK. A new concept and finite-element study on dentin bond strength tests. Dent Mater 2016; 32: e238-e250. 